Revista da Associação Nacional dos

Programas de Pós-Graduação em Comunicação

(e) compós

www.compos.org.br

\title{
Reflexões sobre as Mulheres de Roy Lichtenstein da década de 1960
}

\author{
Flávia Ataide Pithan ${ }^{1}$
}

RESUMO: A década de 60 foi revolucionária e turbulenta. Ocorreram importantes fatos sociais e mudanças tecnológicas. A libertação das mulheres ganhou força nesse período. Na esfera da comunicação visual ocorreu o movimento estilístico conhecido como Arte Pop, do qual participou Roy Lichtenstein. As mulheres pintadas por ele naquela época ajudam a difundir, relatar e perpetuar a história daquele tempo de maneira coerente. Ele pintou o universo paradoxal, híbrido e fragmentado no qual suas personagens estavam inseridas. Após a análise proposta por este artigo, essas características, também presentes na atualidade, são mais facilmente compreendidas.

Palavras-chave: Lichtenstein, Arte Pop, pós-modernidade.

ABSTRACT: The 60's were a revolutionary and turbulent decade when important social and technological changes took place. Women liberation gained strength in this period of time. On the visual communication sphere occurred the stylistic movement known as the Pop Art, which Roy Lichtenstein participated. Women painted by him in that time still help to disseminate, relate and perpetuate the history of that time in a coherent way. He painted the paradox, hybrid and fragmented universe on which his characters were inserted. After the analysis purposed by this article, those characteristics, also present nowadays, are more easily understood.

Key words: Lichtenstein, Pop Art, postmodern.

RESUMEN: La década de 60 ha sido revolucionaria y turbulenta. Ocurrieran importantes hechos sociales y cambios tecnológicos. La libertación de las mujeres cobró fuerza en este período. En la esfera de la comunicación visual ocurrió el movimiento estilístico conocido como arte pop, del cual participó Roy Lichtenstein. Las mujeres pintadas por él en aquella época ayudan a difundir, relatar y perpetuar la historia de aquel tiempo de manera coherente. Él pintó el universo paradójico, híbrido y fragmentado en el cual sus personajes estaban insertadas. Después del análisis propuesto en este artículo, esas características, también presentes en la actualidad, son más fácilmente entendidas.

Palabras-clave: Lichtenstein, Arte Pop, posmodernidad.

RÉSUMÉ: La décennie de 1960 fut révolutionnaire et turbulente, marquée par d'importants faits sociaux et des changements technologiques. Pendant cette période, la libération des femmes prit de l'essor. Dans la sphère de la communication visuelle, le mouvement stylistique Pop Art vit le jour, avec notamment la participation de Roy Lichtenstein. Les femmes peintes par l'artiste à cette époque aident à diffuser, à relater et à perpétuer l'histoire de ce temps de manière cohérente. Il a peint l'univers paradoxal, hybride et fragmenté dans lequel se situaient ses personnages. L'analyse proposée par cet article permet de mieux comprendre ces caractéristiques, également présentes dans le monde contemporain.

Mots-clés: Lichtenstein, Pop Art, post-modernité. 


\section{Introdução}

Presencia-se um período que apresenta características distintas de outros momentos históricos já vivenciados pela humanidade, do ponto de vista antropológico, caso se considere os vários campos que compõe uma sociedade: a arte, a comunicação, as ciências biológicas, a tecnologia, a cultura,...

Vários fatores propiciaram, e ainda estão propiciando, a formatação desta nova condição. A alteração do paradigma de produção tecnológica trouxe conseqüências nas áreas do conhecimento e da produção. Além de maior flexibilidade às verdades unificadoras (pertencentes ao Século XX e ao mundo pós-Iluminismo), a fragmentação dos tempos e espaços culturais proporcionou a afirmação de outros comportamentos sociais, de novas visualidades e de tendências de valores antes não admitidos pelo homem moderno.

Características como o popular, o passageiro, o banal, o emocional, o subjetivo, a identificação, o hibridismo, o presenteísmo e o hedonismo passam a fazer parte do repertório que define a atualidade. De acordo com Maffesoli (1997) o importante não é mais negar padrões anteriores como fazia o homem moderno. O homem pós-moderno, como ele denomina, é um ser mimético, que se transforma segundo as situações e as relações com os seus grupos.

Calabrese (1987) não concorda com o termo pós-modernidade, pois acredita que tenha perdido o significado original e se converteu em slogan ou em selo para operações criativas, sendo ainda um termo muito genérico e equivocado. Defende o uso de neobarroco para nomear este tempo aparentemente confuso, fragmentado, indecifrável. O autor também acredita que existe "em nossa época uma mentalidade, um horizonte comum de gosto, e não a sensação de quais são as melhores obras” (CALABRESE, 1987, p. 11). O termo para ele consiste na "busca de formas - e sua valorização - na qual assistimos a uma perda da integridade, da globalidade, da sistematização ordenada em prol da instabilidade, da polidimensionalidade, da mutabilidade” (ibid., p. 12). A evidência é que a sociedade contemporânea manifesta sua produção intelectual independentemente da qualidade e da função, mas vislumbra um horizonte comum no gosto como se expressa, se comunica e troca essas produções. “Também a primeira vista 
Revista da Associação Nacional dos

Programas de Pós-Graduação em Comunicação

\section{(e) compós}

www.compos.org. br

se intui que a sociedade atual parece difusamente penetrada por uma espécie de estetização de massa como nenhuma outra anteriormente esteve” (ibid., p. 28).

\section{A Arte Pop e Roy Lichtenstein}

Embora as transformações da pós-modernidade (ou neobarroco) tenham começado a partir do final do século XIX, na esfera das artes esta nova tendência foi substancialmente difundida nas décadas de 50 e 60 do século XX. Kern (2006) salienta que neste período "quando os paradigmas do conhecimento científico começaram a ser repensados, a arte moderna vive uma fase de crise e abandono das premissas que a institucionalizaram” (p. 8). As categorias da arte anterior como pureza, autonomia, originalidade, autoria e gosto universal foram enfraquecidas diante do hibridismo, da mescla da arte com outras atividades práticas, de sua pluralidade e banalização.

Estas mudanças remetem a um dos movimentos estilísticos frutos desta época que ocorreu na Europa e nos Estados Unidos simultaneamente e ficou conhecido como Arte Pop. Algumas características até então valorizadas pela arte moderna foram rompidas. Surge então a denominada arte pós-moderna. Pedrosa (1975) fala que sob a estética do pop ou da antiarte pairavam tantas finalidades diferentes que o levaram a falar em “arte pós-moderna”. Percebe-se hoje o impacto dessa orientação artística (fruto de nova orientação cultural) visto que a própria história cultural "não estabelece a distinção entre arte maior e menor, valoriza os monumentos públicos, o design, a fotografia e a cultura de massa, que até então não eram focalizados” (KERN, 2006, p. 9).

Os artistas desse movimento praticamente não utilizavam temas oriundos da imaginação, eles não criavam: olhavam na sua volta e escolhiam. Assim, utilizavam temas populares, desde produtos encontrados no supermercado até as estrelas do cinema hollywoodiano. Neste contexto vale o pensamento de Ferry (1994), para o qual

[...] as vanguardas [...] vivem da banalidade cotidiana; se não houver banalidade, não haverá vanguarda, já que a vanguarda é o movimento pelo qual um pequeno grupo, uma elite, animada por um projeto novo, rejeita radicalmente o conformismo ambiente, as idéias aceitas, as heranças da tradição (p. 271). 
Revista da Associação Nacional dos

Programas de Pós-Graduação em Comunicação

\section{e compós}

www.compos.org. br

As novas possibilidades abertas por este movimento estilístico, também foram utilizados como reação contra o Expressionismo Abstrato. "Este tipo de pintura baseavase na idéia de que a arte deveria ser um documentário direto dos impulsos interiores e das emoções do artista, e era portanto intensamente pessoal e espiritual, o oposto da arte pop” (WILSON, 1975, p. 8).

A Arte Pop proporcionou um meio comunicacional extremamente híbrido, fragmentado, abrindo caminho para experimentações visuais. Essa arte nascida da mídia popular, aboliu a fronteira entre arte de elite e arte popular, característica utilizada por seus artistas que, além de rejeitaram a idéia de que arte e vida deveriam ficar separadas, buscavam inspiração na cultura de massa, no gosto popular, no kitsch, na linguagem da propaganda, enfim, em coisas que até então eram descartadas pelas belas artes.

Diante disso, pode-se inferir que a Arte Pop afetou o curso posterior da arte de todo o mundo e reconfigurou o entendimento da cultura do século XX. Evitou a rigidez e as censuras de algumas manifestações do modernismo em favor de uma "arte que era visual e verbal, figurativa e abstrata, criada e apropriada, artesanal e produzida em massa, irônica e sincera” (MCCARTHY, 2002, p. 14). Ela não se opunha totalmente à arte moderna ou modernista anterior e era falso que se propunha a ser entendida por qualquer pessoa. De acordo com Mccarthy (2002), foi um movimento completamente culto com uma consciência aguda de seus antecedentes históricos. Deve-se reconhecer pelo menos uma das ironias históricas desse movimento notado por seu interesse pela ironia. Esta arte que tirou inspiração da cultura de massa "passou a encorajar em seus observadores e mesmo a exigir deles um alto grau de conhecimento de história” (ibid., p. 15).

Pedrosa (1975) ressalta que os popistas percebiam o fun do meio urbano e o exaltavam. Lichtenstein, citado pelo autor, dizia que "na paródia a implicação é de perversidade, e eu sinto que na minha própria obra não é esta minha intenção. Porque não desgosto o mundo que estou parodiando. [...] As coisas que aparentemente parodiei, na realidade as admiro" (p. 177).

Segundo Wilson (1975) “esta idéia, de vital importância, de que artistas devem lidar com o mundo do presente e com a vida, assim como com sua arte, é também a base da arte pop” (p. 4). Além disso, por ser filha de Nova Iorque e Londres, seu mundo é o 
Revista da Associação Nacional dos

Programas de Pós-Graduação em Comunicação

\section{(e) compós}

www.compos.org. br

das grandes metrópoles. “O pop está enraizado no ambiente urbano. Não só enraizado: o pop contempla aspectos especiais daquele ambiente, aspectos que por suas associações e nível cultural pareciam à primeira vista incompatíveis como temas para arte” (p. 5). O artista pop trata esses materiais de modo muito especial, utilizando o que quer que seja apenas como “motivo”, como pretexto para um quadro, “...como para Cézanne uma maçã é uma natureza morta”. Porém

[...] enquanto num Cézanne o modelo é tradicional e familiar para o espectador, sendo mais fácil para este se abstrair do modelo e se concentrar nas qualidades formais de pintura, na arte pop o modelo não é nunca tradicional, é de uma espécie que antes nunca tinha sido utilizada como base para arte, e portanto atrai fortemente a atenção do espectador (WILSON, 1975, p. 5).

A solução dos artistas pop foi trazer a arte firmemente de volta ao contato com o mundo e a vida, e encontrar temas que assegurassem certo grau de aceitação. É uma ironia da história da arte, como Roy Lichtenstein analisa com sarcasmo, citado por Wilson (1975), que a “Arte Pop de Nova Iorque se tenha tornado tão comercial quanto o Expressionismo Abstrato, senão mais, e na metade do tempo” (ibid., p. 9).

A Arte Pop é a semente de uma estética mais flexível, que absorve e mistura estilos, dando origem a uma arte híbrida, que sobrepõe temas, técnicas, materiais. Esta é uma característica da contemporaneidade, que valoriza o mundo das imagens.

A obra de Roy Lichtenstein ratifica o que vem sendo exposto até aqui. Tematicamente sua obra mistura realidade com ilusão, expõe sonhos e desejos de pessoas que viviam cercadas pelos estereótipos transmitidos pela mídia; revela situações cotidianas comuns e outras inusitadas e fantasiosas; trabalha o mundo comum, a banalidade, a vulgaridade e o cotidiano; reforça questões sociais, políticas e ideológicas de sua época. Enfim, ele usava a arte para relatar e denunciar através de suas imagens o universo da sociedade da comunicação de massa, bombardeada pelos produtos de consumo norte-americanos. As próprias imagens do cotidiano que ele reproduzia eram originalmente concebidas para a comunicação em massa, retiradas de revistas, catálogos de vendas, entre outros. 
Revista da Associação Nacional dos

Programas de Pós-Graduação em Comunicação

\section{(e) compós}

www.compos.org.br

Ele começou a pintar histórias em quadrinhos por volta de 1960, depois de ter passado pelo Expressionismo Abstrato. De acordo com Wilson (1975), indagado por que tinha escolhido uma temática de material aparentemente tão degradado e inestético, Lichtenstein, dando talvez uma resposta por todos os artistas pop, disse que "os aceitava porque eles estavam aqui, no mundo... Os quadrinhos e letreiros são temas interessantes. $\mathrm{Na}$ arte comercial pode-se encontrar coisas úteis, fortes, vitais” (p. 9-10).

Lichtenstein tinha então encontrado o seu "território artístico" com a adaptação do tema impresso. Imagens banais e sem crédito como pequenos anúncios de páginas amarelas, ilustrações de artigos vendidos por catálogos, imagens de guerras tiradas da banda desenhada de ação e os romances indicados para adultos tomam conta da obra deste artista, que realizou sua primeira exposição individual em 1962 na galeria de Leo Castelli (HENDRICKSON in BERCLAZ, 2004, p. 6).

Esse artista ajudou a modificar a linguagem artística de seu tempo, utilizando com humor o conceito de arte na era da reprodução em massa. Em suas obras expressava a preocupação em encontrar uma justificativa, um sentido, um nexo para o estilo de vida que o cercava. Isso posto, e considerando que todos os meios de expressão funcionam como linguagem, pode-se dizer que sua linguagem gerou documentos históricos que possibilitam a reconstrução global da cultura daquele período.

[...] todo objeto carrega consigo uma relação de significação, que passa a representar uma convenção cultural, onde se manifestam as produções de sentido de dada sociedade, em dado tempo e espaço. [...] Entender, analisar o objeto implica num processo de conhecimento de códigos, tecidos significantes que interagem em específica produção de cultura. Nesta perspectiva, faz-se necessário entender o objeto como linguagem e de codificá-lo a partir de elementos diversificados que retratam as nuances textuais, contextuais e intertextuais (ANTONINI, 2006, p. 3).

\section{Breve análise das mulheres de Roy Lichtenstein da década de 1960 e suas implicações na contemporaneidade}

A figura feminina é muito utilizada por Lichtenstein em seus trabalhos. As obras nas quais a mulher é representada e que aqui serão analisadas datam do início da década de 60 do século XX. Essas pinturas possibilitam desvendar alguns traços importantes daquela época, considerada como o início de uma nova configuração cultural, artística e até estilística. 
Revista da Associação Nacional dos

Programas de Pós-Graduação em Comunicação

\section{(e) compós}

www.compos.org.br

Para Didi-Hubermann (2006) estar à frente de uma imagem não significa apenas interrogar-se sobre o que está na frente dos olhos, mas também deter-se diante do seu tempo. "Não é evidente que a “chave” para compreender um objeto do passado se encontra no próprio passado, e mais ainda, no mesmo passado do objeto?” (p. 16). Esta é a busca da concordância eucrônica. O autor evidencia que o anacronismo é necessário e fecundo "quando o passado se mostra insuficiente, e constitui inclusive, um obstáculo para a compreensão de si mesmo” (p. 22). Por isso, em alguns casos, não se pode contentar com fazer uma história da arte sob o ângulo da “eucronia”, isto é, sob o ângulo convencional do "artista e seu tempo" (p. 23).

Marc Bloch (padre da escola dos Annales), citado por Didi-Huberman (2006), acredita que não apenas é impossível compreender o presente ignorando o passado, mas que também é necessário conhecer o presente - apoiar-se nele - para compreender o passado e saber traçar as perguntas convenientes.

Trata-se de considerar todo o contexto sócio-cultural de produção e circulação da obra, não limitando-se a um ou outro tipo de análise. Assim, a produção de conhecimento poderá ser satisfatória. De acordo com Kern (2004), na historiografia da arte de hoje,

[...] a importância reside no mundo social, no papel que a arte exerce neste mundo, no estatuto da obra, nas suas funções e propriedades estéticas. [...] Assim, a História da Arte não é concebida apenas como uma história de obras, formas e artistas, mas como cultura visual produzida por homens e grupos sociais que colaboram nas expressões de sentidos de mundos (p. 132).

Este foi o direcionamento almejado neste trabalho, a interpretação das obras selecionadas considerando o impacto das mesmas no seu tempo, na sua cultura e entre seus grupos sociais, mas também analisando os reflexos daquelas manifestações sócioculturais nos dias de hoje.

Após esses esclarecimentos iniciais, será exposta uma interpretação de 12 obras de Lichtenstein, nas quais a mulher foi considerada como fio condutor para a análise. Algumas hipóteses foram levantadas considerando as características dos trabalhos em paralelo com a conjuntura da época na qual foram produzidos e também considerando a 
Revista da Associação Nacional dos

Programas de Pós-Graduação em Comunicação

\section{(e) compós}

www.compos.org. br

relação dessas imagens com o contexto atual. Cada obra é considerada como forma de expressão ou como um "sistema de signos organizados a partir de uma linguagem construída pelo artista em relação com a cultura e a sociedade a que pertence. Neste sentido, a pintura e as outras artes são fatos sociais” (CALABRESE, 1986, p. 47). Salienta-se, novamente, que não se pretende aqui realizar um ou outro tipo de análise. O que se tem claro é a importante necessidade de analisar as imagens em questão dentro do momento histórico de sua produção e também sua interação com o tempo atual, a pósmodernidade. Compartilha-se do que Menezes (2005) cita como oportuno para analisar as fontes visuais: considerar as dimensões formal, semântica e social, o que ressalta que "o conhecimento artístico e o conhecimento histórico não só podem beneficiar-se mutuamente, como também são interdependentes” (p. 42).

O enfoque da interpretação considera que esses objetos pertencem a uma determinada cultura e conseqüentemente são inseridos em um meio cultural. Dessa forma, buscar-se-á compreender as ligações e relações entre as obras e a sociedade.

Um juízo estético é acompanhado quase sempre por um juízo ético ou passional ou morfológico e vice-versa. Cada indivíduo, grupo ou sociedade não apenas atribui determinados valores, mas também homologações entre diversas polaridades de valoração (CALABRESE, 1987, p. 39).

Calabrese (1986) cita Panofsky, o qual distingue três níveis de significado na obra de arte. O sujeito primário e natural consiste na identificação de formas puras, o secundário ou convencional consiste na identificação dos temas de uma obra e da sua combinação e o terceiro nível, do significado intrínseco ou do conteúdo, consiste na identificação da atitude de fundo num período, numa nação, numa classe, numa cultura que condiciona o artista e é simbolizada na obra. “O primeiro setor é o domínio da identificação dos motivos, o segundo da iconografia, o terceiro da iconologia” (p. 26).

Dando ênfase ao terceiro nível, é preciso atentar-se para a crise políticoideológica vivida nos anos 60. Havia efervescência cultural. Surgiram os movimentos pela paz. Os costumes tradicionais eram contestados pela entrada em cena do mundo jovem: Beatles, Woodstock, Black Power, movimento hippie e feminista. O mundo se envolvia numa grande discussão sobre direitos humanos. Segmentos marginalizados da 
Revista da Associação Nacional dos

Programas de Pós-Graduação em Comunicação

\section{e compós}

www.compos.org.br

sociedade de Nova Iorque se articulavam para fazer valer suas propostas, numa tentativa de diluição de suas inquietações.

De acordo com Hollanda (2006), as décadas de 60 e 70 foram importantes pois abriram espaços e canais de expressão institucionais como uma imprensa feminista, o cinema de mulher e os estudos feministas enquanto área de conhecimento. Neste quadro, a introdução da categoria gênero representou o aprofundamento e a expansão das teorias críticas feministas. O estudo das relações de gênero, agora substituindo a noção de identidade, passou a privilegiar o exame dos processos de construção destas relações e das formas como o poder as articula em momentos datados social e historicamente, variando dentro e através do tempo e inviabilizando o tratamento da diferença sexual como "natural".

De acordo com Giannotti (2006), as mulheres americanas e européias haviam descoberto a pílula e as dos países do Terceiro Mundo a metralhadora nas guerrilhas, lado a lado com os homens. As mulheres americanas se manifestavam contra a Guerra do Vietnã e falavam em Women's Lib (libertação das mulheres). Em suas manifestações feministas falavam de "mística feminina” e queimavam sutiãs nas praças públicas.

De uma maneira geral, a década de 60 foi revolucionária e turbulenta, ocorreram grandes fatos sociais e mudanças tecnológicas: assassinatos, grande revolução no mundo da moda, novos estilos musicais, direitos civis, libertação de mulheres e homossexuais, a guerra do Vietnã, as primeiras expedições à Lua, campanhas de paz, grandes filmes e programas de TV, liberdade sexual. Os indivíduos do pós-guerra formavam um exército de consumidores.

O feminismo vem sendo considerado, no cenário pós-moderno de descrédito das ideologias, como uma das alternativas mais exemplares e concretas para a prática política e para as estratégias de defesa da cidadania.

Nas décadas de 60 e 70, as questões da identidade e diferença foram inegavelmente importantes, tendo conseguido abrir espaços e canais de expressão institucionais como uma imprensa feminista, o cinema de mulher e os estudos feministas enquanto área de conhecimento. Neste quadro, a introdução da categoria gênero 
Revista da Associação Nacional dos

Programas de Pós-Graduação em Comunicação

\section{e compós}

www.compos.org.br

representou o aprofundamento e a expansão das teorias críticas feministas (SHOWALTER, 2006).

Na primeira série de trabalhos selecionados de Roy Lichtenstein a mulher aparece em situações cotidianas ou rotineiras. Trata-se da mulher com compromissos profissionais. Na figura 1, composta por duas situações, aparece uma perna feminina magra, com um sapato de salto, abrindo uma lata de lixo. O tecido xadrez do vestido poderia indicar um uniforme ou um avental de uma empregada doméstica, o que é descartado considerando o sapato usado pela personagem. Trata-se de uma dona de casa realizando suas tarefas cotidianas, mas que não faz apenas isso, caso contrário estaria usando um sapato mais adequado. A dona de casa da década de 60 já possuía facilitadores para suas atividades corriqueiras frutos da evolução industrial, como a lata de lixo que abre com o pé. A figura 2 mostra apenas uma esponja sendo manuseada para limpar uma superfície. A mão indica ser feminina pelos traços e pelas unhas, também atribuindo as atividades deste tipo às mulheres.

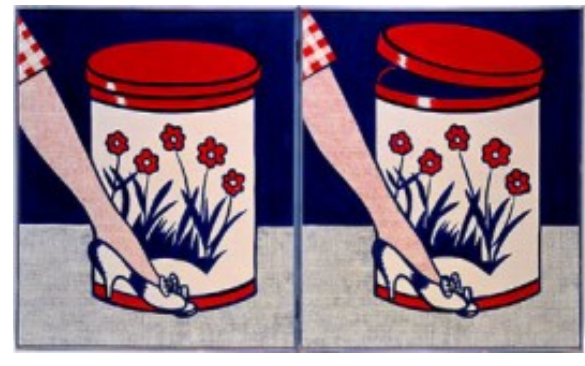

Figura 1: Step-on can with Leg, 1961 Fonte: HENDRICKSON, 1994, p. 30.

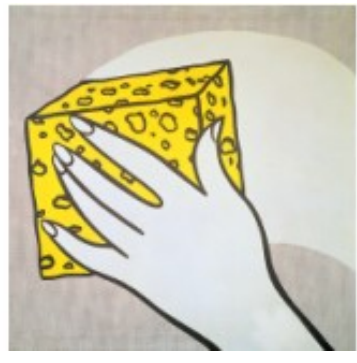

Figura 2: Sponge II, 1962 Fonte: http://www.lichtenstein foundation.org

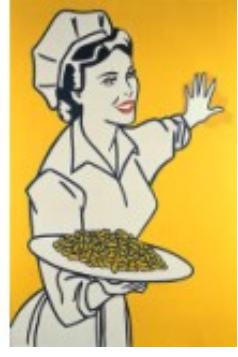

Figura 3: Woman with Peanuts, 1962 Fonte: http://www.lichtensteinfoundation.org

A figura 3 apresenta uma mulher morena servindo amendoins. Devidamente uniformizada, evidencia que seu trabalho é como garçonete. Essa série de obras do artista revela a diversidade das atividades assumidas pelas mulheres já na década de 60. Mulher que já lutava pela sua independência financeira mas não deixava de cuidar do lar, apoiada pelos produtos da produção em massa.

A figura 4, a seguir, representa uma jovem jogando bola. Um olhar mais cuidadoso revela algumas peculiaridades. A jogadora está pegando uma bola. Como está utilizando um maiô pode-se inferir que está jogando na praia. O que chama a atenção é a 
sensualidade da pose e da feição do rosto da jogadora, expressando a vontade de ser notada da personagem, característica encontrada e valorizada por algumas mulheres influenciadas pela mídia já nos anos 60 e ainda seguida por certos grupos sociais nos dias de hoje. Na figura 5 a mulher está tomando banho de banheira sorrindo e com uma esponja na mão. Ação que nem todas as pessoas podem realizar no seu dia visto que é necessário ter uma banheira e tempo para um banho como este, evidenciando certo luxo da personagem. A figura 6 mostra uma menina olhando-se no espelho também sorrindo. Ela pode estar em qualquer lugar, visto que é um espelho de mão. O ato de se olhar no espelho é típico de pessoas que são vaidosas, sugerindo que a moça loira também o seja. Essa seqüência de obras de Lichtenstein revela um mundo possível de mulheres em situações mais fúteis, em oposição às situações da seqüência anterior. Vale salientar que as três personagens são belas e vaidosas, fazendo um paralelo entre uma característica física e outra temperamental, levando o observador a fazer uma ligação entre: para ser bela é preciso ser vaidosa (cuidar-se). O hedonismo fica claro nessas mulheres que valorizam o divertimento e o cuidado com a aparência. Esta característica passou a ser valorizada na pós-modernidade, quando ocorre a libertação de algumas imposições racionais, religiosas e morais do homem moderno.

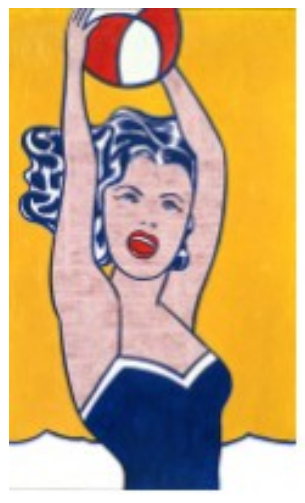

Figura 4: Girl with Ball, 1961 Fonte: HENDRICKSON, 1994, p. 24.

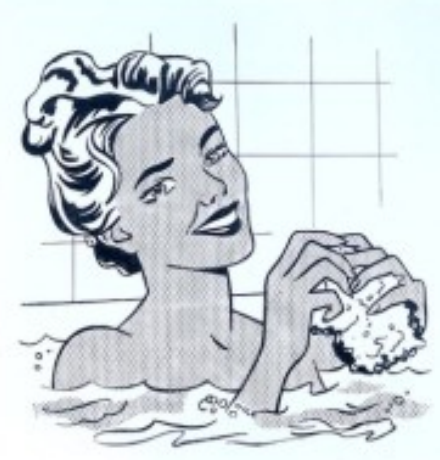

Figura 5: Woman in Bath, 1963 Fonte: http://www.lichtenstein foundation.org

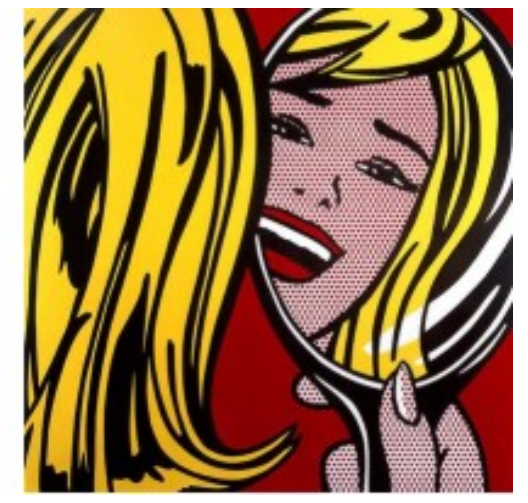

Figura 6: Girl in Mirror, 1964 Fonte: http://www.lichtenstein foundation.org

A figura 7, subseqüente, traz uma figura feminina chorando por um homem que aparece ao fundo, presente em seus pensamentos. Novamente é uma jovem bonita, com lábios carnudos, loira, nariz empinado. Uma mulher frágil que sofre por amor. A figura 8 
Revista da Associação Nacional dos

Programas de Pós-Graduação em Comunicação

\section{(e) compós}

www.compos.org.br

também retrata uma mulher chorando e mergulhada ou envolta por água agitada. Seu pensamento, exposto no balão, revela ao observador que ela está "se afogando num rio de lágrimas”, suas próprias lágrimas. Percebe-se nas palavras seu orgulho, visto que expõe preferir “afundar” a "pedir ajuda de Brad”. Uma análise mais cuidadosa leva até as mulheres que queriam (e querem) ser independentes do gênero masculino e às vezes acabavam sofrendo desnecessariamente para não assumir suas fraquezas e limitações. Ilustra a postura de enfrentar os problemas e de mostrar-se forte, exigida ou imposta pelo feminismo da época. Esta postura hoje é valorizada por muitas mulheres, postura também muito difundida pela mídia em filmes, novelas e revistas. Enquanto a primeira sofre de amor, pelo seu romantismo e sentimentalismo, a segunda sofre por ser orgulhosa. Na figura 9 o choro também aparece na personagem deitada. Mais uma vez, trata-se de uma loira, bonita, lábios carnudos e nariz arrebitado. Esta ainda tem olhos azuis delineados. Está refletindo sobre o caminho a seguir diante de algo que começou a acontecer. Pode ser algo profissional, amoroso, social... Ela está com um problema e não tem esperança de resolvê-lo. Revela um comportamento frágil. Muitas mulheres de Lichtenstein aparecem chorando. Por um lado, o artista pode ter sido irônico ao pintar tanto esta atitude, típica do gênero feminino, como que alertando ou repudiando esta ação feminina. Ou, pelo contrário, o artista pode ter apenas representado as mulheres de sua realidade, as mulheres que o rodeavam e que talvez até admirasse.

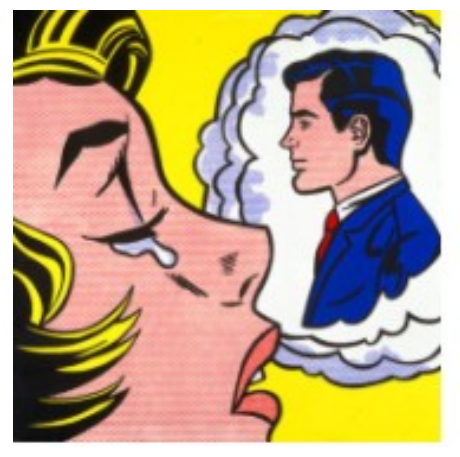

Figura 7: Thinking of Him, 1963 Fonte: http://www.lichtensteinfoundation .org

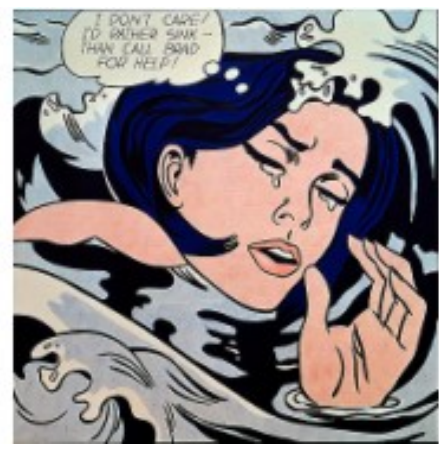

Figura 8: Drowning Girl, 1963 Fonte: HENDRICKSON, 1994, p. 31.

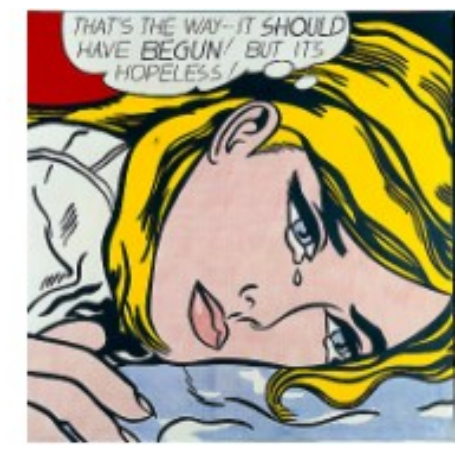

Figura 9: Hopeless, 1963

Fonte:

http://www.lichtensteinfoundation.org 
A série de imagens a seguir difunde as várias atitudes e comportamentos femininos diante de uma mesma ação. Embora nas três imagens o beijo seja o fio condutor, pode-se perceber a diferença de atitude dessas mulheres. Na figura 10 uma jovem, considerando sua camiseta, entrega-se ao beijo sem cerimônia. Na figura 11 a personagem está aliviada, chorando de emoção durante o beijo. A mulher da figura 12 é a mais comedida e também a mais velha, considerando seu penteado. A postura dessas três mulheres foi determinada pelo contexto, pelo ambiente. A primeira está em algum lugar ao ar livre, com árvores ao fundo, onde seria permitido e aceitável um comportamento mais despreocupado. Em oposição, a última está em uma base aérea, o que exige um comportamento discreto e controlado. Novamente as três apresentam as características estéticas mais marcantes das mulheres pintadas por Lichtenstein naquela época: são loiras, bonitas, lábios carnudos. O protótipo da beleza feminina tão divulgado pela mídia desde aquele tempo, que continua a ser valorizado nestes dias. Caso contrário não se presenciaria o número explosivo de cirurgias plásticas, a proliferação das academias e a valorização crescente do culto ao corpo.

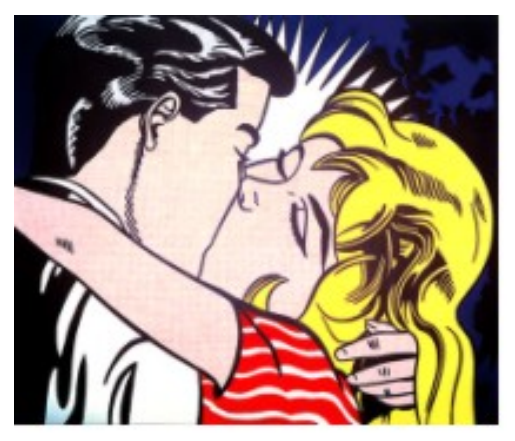

Figura 10: Kiss II, 1962

Fonte:

http://www.lichtensteinfoundation.org

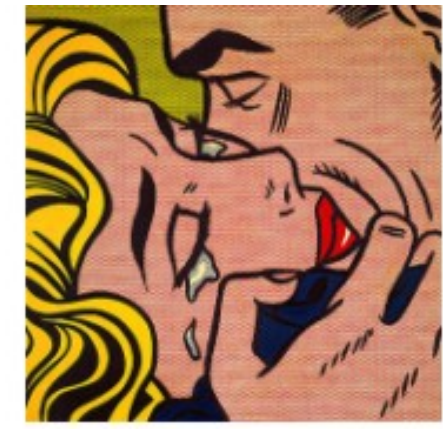

Figura 11: Kiss V, 1965

Fonte: http://www.lichtenstein foundation.org

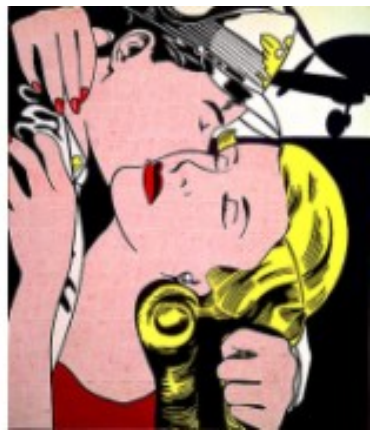

Figura 12: The Kiss, 1962 Fonte: HENDRICKSON, 1994, p. 35

\section{Conclusões}

Após estas breves interpretações alguns pontos ficam evidentes. Lichtenstein com suas inúmeras mulheres pintadas na década de 60 do século XX, produziu importantes documentos culturais daquele tempo. Sua crítica ou o seu fascínio ao esteriótipo da beleza americana fica evidente. Ele pintou algumas mulheres desenvolvendo atividades, trabalhando, onde preferiu representar apenas uma parte do 
Revista da Associação Nacional dos

Programas de Pós-Graduação em Comunicação

\section{e compós}

www.compos.org. br

corpo ou uma mulher morena, mas a maioria de suas obras são com mulheres bonitas, loiras, narizes empinados, lábios carnudos, maquiadas. Expressam a futilidade, o exagero e a falsidade da realidade que o cercava. Evidenciou também a mulher com sentimentos sinceros, com fraquezas ou com convicções. Sua obra refletia a sociedade daquele tempo, que vinha transformando e fragmentando os comportamentos sociais antes impostos e cobrados pela sociedade rígida e racional moderna, sociedade de papéis sociais definidos e que punia comportamentos que não condiziam com o senso comum. Hoje esta sociedade absorveu todos essas atitudes femininas, apresentando um híbrido de comportamentos femininos aceitos. Trata-se apenas de uma questão de escolha, permitida pela sociedade pós-moderna.

Observar sua obra nos dias de hoje leva a uma reflexão sobre a trajetória cultural percorrida desde os anos 1960 não apenas pelas mulheres. Então volta-se a questão inicial exposta neste texto, de que neste tempo vive-se algo novo. Ao mesmo tempo que as mulheres (e os homens) buscam a superação pessoal e a afirmação e o reconhecimento profissional, a sociedade espera que tenham também algumas atitudes convencionais ou típicas do passado, como constituir uma família ou ser praticante de uma religião. O cidadão pós-moderno está inserido numa sociedade paradoxal, fruto da modernidade a qual

[...] apesar do seu discurso de ruptura e do seu anseio de liberação, acabou por fortalecer uma idéia extrema de moralidade ou, em outros termos, uma nova moral. [...] Ao mesmo tempo que pregava a emancipação, a modernidade temia o hedonismo e a dimensão total da liberdade. Havia, no fundamento da moderno, uma obsessão por um mundo perfeito e ordenado (LIPOVETSKY, 2000, p. 11).

Esta realidade está mudando. Lipovetsky (2000) cita duas hipóteses de análise

para as sociedades ocidentais contemporâneas. Em uma, sobressai-se o consumo, a uniformização dos modos de vida, a globalização econômica, a hegemonia de certas marcas e a massificação. Na outra, observa-se a liberação em relação à tradição, às instituições, à Igreja e ao sagrado, como o conseqüente aumento da autonomia individual. “Abordar somente a manipulação é uma forma de manipular as pessoas. Estamos vivendo 
Revista da Associação Nacional dos

Programas de Pós-Graduação em Comunicação

\section{(e) compós}

www.compos.org.br

uma revolução individualista subterrânea. Através dela, a condição de existência está sendo mudada” (ibid., p. 11).

Em ambas hipóteses, e de acordo com Paviani (2003), nenhuma sociedade deve descuidar-se da formação do gosto estético de seus cidadãos, especialmente se for uma sociedade democrática. Isso tornou-se evidente com o desenvolvimento destas análises.

Bayer (1978) acredita, por exemplo, que pode-se imaginar a mentalidade e a sensibilidade dos homens que criaram as obras na arte pré-histórica, mesmo que fossem inconscientes dessa mentalidade. Disto surge sua crença que uma obra de arte supõe sempre uma direção das energias do homem, que corresponde ao que se infere da estética. Desta forma, analisando os temas da estética da Arte Pop, pode-se dizer que alguns de suas características são extremamente atuais. Não existem apropriações proibidas. Hoje os intercâmbios entre as áreas de conhecimento, bem como as trocas de informações, de temas, de conceitos e de ideologias, ocorrem em todas as direções. Muitos artistas, publicitários, designers ou jornalistas apropriam-se de outras áreas para desenvolver seus trabalhos, como os artistas da Arte Pop o fizeram com o cotidiano, cada um seguindo por diferentes caminhos, mas todos aproveitando as idéias fornecidas pela vida cotidiana real, misturando-as à história e à tradição de determinado povo.

O estético ultrapassa o âmbito da obra de arte; esta é o lugar, a condição material que possibilita a manifestação do estético. As obras de arte são um modo privilegiado, um meio estratégico para o estético se tornar realidade. Não têm monopólio desta função. Ao contrário, há uma solidária união entre o fenômeno estético e os meios de comunicação (PAVIANI, 1987, p. 28-29).

Paviani (1987) ressalta o fato de que o fenômeno estético é um tipo de experiência humana fundamental, sem a qual o homem não existe, sendo esta a modalidade de relação que se tem com os outros e o mundo. "É uma atitude, um comportamento, uma qualidade, predominantemente sensível, que emana do contato do homem com as obras, sejam elas artísticas, técnicas ou naturais” (p. 29). Porém, para o autor, isto não significa que o estético tenha só dimensão individual, mas que só poderse-á falar em norma estética, em valor estético, quando esta atitude assumir uma consciência coletiva, através do modo comum de sentir de um grupo. Por isso pode-se 
Revista da Associação Nacional dos

Programas de Pós-Graduação em Comunicação

\section{e compós}

www.compos.org. br

definir as características da função estética, mas jamais separá-las de outras funções: sociais, morais, religiosas, políticas, etc.

Vale citar o pensamento de Ferry (1994):

O que caracteriza a arte contemporânea não é certamente o fato de que as obras atestem menos talento do que as do passado. Ocorre simplesmente que a pretensão da arte talvez tenha mudado: para muitos artistas, hoje não se trata mais de descobrir o mundo [...] ou de utilizar a arte como um instrumento para o conhecimento de uma realidade estranha a eles mesmos. Muito pelo contrário, parece que, em muitos casos [...] a obra seja definida pelo próprio artista como um prolongamento de si mesmo (p. 26-27).

Cabe à arte "com sua linguagem plurissensorial exprimir o complexo social, o clima cultural de desintegração e o sentido de fragmentação do homem e da sociedade contemporânea” (PAVIANI, 1987, p. 24). “As expressões culturais resultam do relacionamento do homem com a natureza e do homem com os demais homens, primeiro, num processo de transformação, e segundo num processo de comunicação” (ibid., p. 38). Por isso, de acordo com Lipovetsky (2000) está-se mergulhado num “imaginário puro, livre da verossimilhança, aberto à criatividade sem entraves, longe do culto da objetividade das coisas” (p. 8). Como conseqüência, a revolução perceptiva se dá em mão dupla: "o mundo transformou-se para que se pudesse atingir essa situação. E isso influi sobre o imaginário das pessoas, aguçando-lhes o apetite pelo lúdico, pelo teatral, pelo espetáculo” (p. 9).

Roy Lichtenstein desperta o interesse do observador com suas pinturas e o leva a uma reflexão sobre os temas que escolheu devido sua obra representar temas enraizados ao cotidiano, familiares ao conhecimento desses atuais observadores. Manifestações artísticas como essas são fundamentais pois comunicam e perpetuam a história de determinado período e cultura. Salienta-se que essa análise apresentou apenas algumas possibilidades interpretativas. O que ficou evidente foi a coerência de Lichtenstein ao retratar a mulher da década de 1960: de um lado as mulheres influenciadas pela mídia e pela sociedade de consumo, de outro as que lutavam pela efetivação de sua independência e por direitos iguais. Comportamentos distintos existentes atualmente, que podem parecer contraditórios mas que às vezes compõem uma mesma personalidade. Ele 
pintou as mulheres com suas qualidades e também com seus defeitos, com suas certezas e medos; pintou a mulher daquela época de ruptura, de mudança e de abertura para novos caminhos, deixando evidências de que já estava germinando nos anos 60 a condição na qual se vive hoje: paradoxal, híbrida, fragmentada, inclusiva,... A cultura pós-moderna.

\section{REFERÊNCIAS BIBLIOGRÁFICAS}

ANTONINI, Eliana Pibernat. Das teorias e práticas discursivas. De uma possível metodologia semiótica aplicada à Comunicação. UNIrevista - Vol. 1, n 3: julho 2006.

BAYER, Raymond. História da Estética. Lisboa: Editorial Estampa, 1978.

CALABRESE, Omar. A linguagem da Arte. Lisboa: Editorial Presença, 1986.

. La Era Neobarroca. Madrid: Cátedra, 1987.

BERCLAZ, Ana Paula Soares. A Memória Visual dos Quadrinhos de Lichtenstein na Arte Pop. Trabalho apresentado no Intercom 2004, PUC-RS. Porto Alegre, 2004.

DIDI-HUBERMAN, Georges. Ante el Tiempo. Buenos Aires: Adriana Hidalgo editora, 2006. FERRY, Luc. Homo Aestheticus: a invenção do gosto na era democrática. São Paulo: Ensaio, 1994.

GIANNOTTI, Vito. O Dia da Mulher nasceu das mulheres socialistas. Disponível em $<$ http://www.piratininga.org.br/memoria/mulheres-vito.html> acessado dia 13/04/2007.

HENDRICKSON, Janis. Roy Lichtenstein. Köln: Taschen, 1994.

HOLLANDA, Heloísa Buarque de. Feminismo em Tempos Modernos. Disponível em $<$ http://acd.ufrj.br/pacc/literaria/Introfem.html> acessado em 6/05/2007.

KERN, Maria Lúcia Bastos. História da Arte e a construção do conhecimento. Artigo no prelo. Anais do XXVI colóquio Brasileiro de História da Arte. São Paulo, outubro de 2006.

Historiografia da Arte: Revisão e Reflexões face à Arte Contemporânea. Porto Alegre: Porto Arte, v. 12, nr. 21, nov. / 2004.

LIPOVETSKY, Gilles. Sedução, publicidade e pós-modernidade. Revista FAMECOS mídia, cultura e tecnologia, $n^{\circ} 12$. Porto Alegre, junho de 2000.

MAfFeSOLI, Michel. A Transfiguração do Político. Porto Alegre: Sulina, 1997.

MENESES, Ulpiano Bezerra de. Rumo a uma "história visual". In: MARTINS, José de S.; ECKERT, Cornelia; NOVAES, Sylvia (orgs.). O imaginário e o poético nas Ciências Sociais. Bauru: Edusc, 2005. 
Revista da Associação Nacional dos

Programas de Pós-Graduação em Comunicação

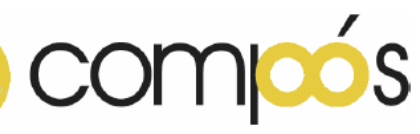

www.compos.org.br

McCARTHY, David. Arte Pop. São Paulo: Cosac\&Naify, 2002.

PAVIANI, Jayme. A Arte na Era da Indústria Cultural. Porto Alegre: PyR Edições, 1987.

Estética mínima: notas sobre arte e literatura. Porto Alegre: Edipucrs, 2003.

PEDROSA, Mário. Mundo, homem, arte em crise. São Paulo: Perspectiva, 1975.

SHOWALTER, Elaine. Feminismo em Tempos Pós-Modernos. Disponível em $<$ http://acd.ufrj.br/pacc/literaria/Introfem.html> acessado dia 13/04/2007.

WILSON, Simon. A arte pop. Barcelona: Labor do Brasil, 1975.

${ }^{1}$ Doutoranda do Programa de Pós-graduação em Comunicação Social da PUCRS. 